\title{
Evaluasi Kualitas Tanah Sawah Intensif dan Sawah yang Dikonversikan untuk Kebun di Subak Kesiut Kerambitan Tabanan
}

\author{
I DEWA MADE ARTHAGAMA*) DAN I MADE DANA
}

Program Studi Agroekoteknologi Fakultas Pertanian Universitas Udayana

J1. PB. Sudirman, Denpasar 80231 Bali

*)E-mail: arthagama@unud.ac.id

\begin{abstract}
Evaluation Quality of Intensif Paddy Soils and Conversion Paddy Soils to Garden at Subak Kesiut Kerambitan Tabanan. This experiment conducted to evaluate intensif Paddy Soils and conversion paddy soils to garden at SubakKesiut Kerambitan Tabanan. There were two steps applied in this study including field survey to determine the research area and points soils sampling; analysis soils properties are: physic, chemistry and soils biology for get minimum data set to determine the soil quality at Laboratory of Soils and Enveronment Faculty of Agriculture Unud. The results of this study showed: the soil quality of intensif paddy soils is better than conversion paddy soils to garden, that showed with SQR at intensif paddy soil is 18 and at conversions paddy soil is 25 . The limiting faktor at conversion paddy soils to garden is $\mathrm{P}$ available, there are less than at intensif paddy soils.
\end{abstract}

Keywords: soil quality, intensif paddy soils, conversion paddy soils to garden

\section{PENDAHULUAN}

Sawah adalah lahan pertanian yang secara fisik permukaan lahannya rata, dibatasi oleh pematang, serta dapat ditanami padi, palawija atau tanaman budidaya lainnya. Kebanyakan sawah digunakan untuk bercocok tanam padi (Sofyan $d k k$, 2007). Untuk keperluan ini, sawah harus mampu menyangga genangan air karena padi memerlukan penggenangan pada periode tertentu dalam pertumbuhannya. Untuk mengairi sawah digunakan sistem irigasi dari mata air, sungai dan air hujan. Pada lahan yang memiliki kemiringan tinggi, sawah dicetak berteras untuk menghindari erosi dan menahan air.

\section{Lahan sawah di Bali menyusut 800} hingga 1000 hektar/tahun (Suparta,2017). Penyusutan terbesar terjadi di Kota Denpasar, Badung dan Tabanan. Tingginya alih fungsi lahan sawah antara lain didorong oleh kebijakan pemerintah Kabupaten/Kota yang membolehkan alih fungsi lahan walaupun pemerintah Provinsi Bali melarangnya alih fungsi sawah 
I DEWA MADE ARTHAGAMADAN I MADE DANA. Evaluasi Kualitas Tanah Sawah Intensif dan...

tersebut. Alih fungsi dan konversi lahan sawah akanterus terjadi jika pemerintah daerah tidak membuat aturan baru yang membatasi perubahan fungsi sawah menjadi perumahan dan konversi ke hal yang lain.

Sistem pengelolaan yang kurang tepat menyebabkan menurunnya produktivitas lahan sehingga produksi tanaman tidak optimal, ini menunjukkan tanah tidak berfungsi sebagai mana mestinya. Tanah yang tidak berfungsi dengan baik menyebabkan terjadinya penurunan kualitas tanah. Penuruanan kualitas tanah disebabkan oleh kurangnya pengembalian bahan organik, penggunaan agrokimia yang kurang tepat, intensitas tanam yang tinggi, pengairan yang tidak teratur mengakibatkan terjadinya perubahan sifat fisik, kimia dan biologi tanah (Adnyana, 2008). Kualitas tanah yang baik adalah kondisi tanah yang menggambarkan tanah mempunyai sifat fisik, kimia, dan biologi tanah yang baik, serta produktivitasnya tinggi secara berkelanjutan (Utomo, 2002; Reintjes 1999).

Luas Sawah di Subak Kesiut Kerambitan Tabanan awalnya 60 ha dan kini tinggal 50 ha, hal ini sebagai akibat adanya konversi lahan sawah dijadikan kebun dan juga alih fungsi lahan untuk tempat hunian. Menurut pengurus Subak Kesiut adanya konversi lahan sawah menjadi kebun akibat kurangnya irigasi untuk lahan sawah di Subak tersebut.

Tahapan penelitian yang dilakukan yaitu penjajagan lapangan untuk penentuan titik sampel sebagai pewakil untuk penentuan kualitas tanah sawah dan yang dikonversikan menjadi kebun. Selanjutnya pengambilan sampel ke lapangan dengan seperangkat alat pengambilan sampel tanah seperti Bor Belgi, ring sampler, pisau lapang ,palu, plastik kantong dan seperangkat alat-alat tulis. Selanjutnya sampel tanah dibawa ke Lab Tanah dan Lingkungan untuk preparasi untuk persiapan dilakukan analisis lab.

Dengan latar belakang tersebut di atas, evaluasi terhadap kualitas tanah sangatlah penting artinya untuk dapat dijadikan acuan guna pengelolaan lahan yang masih ada agar bisa dijadikan pertimbangan untuk mencegah bertambahnya alih fungsi lahan serta konversi lahan untuk peruntukan lainnya.

\section{BAHAN DAN METODE}

Penelitian ini dilaksanakan di Subak Kesiut, Desa Kesiut,Kerambitan ,Tabanan dengan pengkodean penelitian: Sawah Intensif (SI) ;Konversi Sawah menjadi Kebun (SK) dan analisi sifat fisik, kimia dan biologi tanah dilakukan di Lab Konsentrasi Tanah dan Lingkungan Fakultas Pertanian Universitas Udayana di Denpasar. Analisis 
tanah di Laboratorium meliputi : penetapan KTK dan KB metode ekstraksi NH4 OAc,pH7 $1 \mathrm{~N}, \quad \mathrm{P}$ - tersedia dengan metode Bray 1, C-organik dengan metode Walkley and Black, $\mathrm{pH}$ tanah metode Potensiometri (H2O1:2,5), kadar garam dengan Conductometer $\quad(\mathrm{H} 2 \mathrm{O}$ 1:2,5). Kadar air tanah (\% Gravimetri), Berat Volume (Ring Sampler), Porositas (Ring Sampler), Tekstur tanah metode pipet, Total mikroba dengan pendekatan Respirasi. Penelitian berlangsung selama 3 bulan dimulai bulan Agustus 2018.

\section{Alat dan Bahan}

Bor Belgi untuk mengambil sampel tanah, 2 Ring Sampel, 3. Pisau Lapang, 4. Kantong Plastik untuk Tempat sampel tanah, 5. Alat-alat tulis untuk mencatat kondisi di lapangan Bahan yang digunakan pada penelitian ini antara lain: tanah sampel yang telah diambil di lapang baik di lahan sawah dan lahan kebun yang dikonversi dari lahan sawah, lalu depreparasi di Lab Tanah dan Lingkungan, zat-zat kimia yang diperlukan seperti $\mathrm{H} 2 \mathrm{SO} 485 \%$, $\mathrm{K} 2 \mathrm{Cr} 2 \mathrm{O} 7, \mathrm{H} 3 \mathrm{PO} 4$ pekat, DPA, NH4OAc pH $71 \mathrm{~N}, \mathrm{NaOH} 50 \%, \mathrm{HCl}$, Aquadest.

\section{Analisis Tanah}

Analisis tanah sebagai parameter untuk evaluasi kualitas tanah disajikan pada Tabel 1.

Tabel 1. Parameter Pengamatan Sifat Dasar Tanah

\begin{tabular}{lll}
\hline Parameter & Satuan & Metode \\
\hline $\begin{array}{l}\text { Sifat Fisik } \\
\text { 1. Tekstur tanah }\end{array}$ & $\%$ & $\begin{array}{l}\text { Metode pipet } \\
\text { Gravimetri }\end{array}$ \\
2. Bobot isi & $\mathrm{gcm}^{-3}$ & Ring sampler \\
3. Porositas & $\%$ & \\
Sifat Kimia tanah & & Potensiometer $(\mathrm{H} 2 \mathrm{O} 1: 2,5)$ \\
4. $\mathrm{pH}$ & $\%$ & Destilasi Kjeldahl \\
5. N-total & $\mathrm{ppm}$ & Bray-1 \\
6. P-tersedia & $\mathrm{me} 100 \mathrm{~g}^{-1}$ & Ekstraksi NH4OAc $1 \mathrm{~N} \mathrm{pH7}$ \\
7. KTK & $\%$ & \\
8. KB & $\%$ & Ekstraksi NH4OAc $1 \mathrm{~N} \mathrm{pH7}$ \\
9. C-organik & & \\
Sifat Biologi tanah & & Simulasi Respirasi tanah \\
10. C-Biomassa mikroba & $\mathrm{mg} \mathrm{CO}^{-1} \mathrm{~kg}^{-1}$ & \\
\hline
\end{tabular}

Sumber (Djajakirana,1998,Sulaeman et al.,2005) 
I DEWA MADE ARTHAGAMADAN I MADE DANA. Evaluasi Kualitas Tanah Sawah Intensif dan...

\section{Analisa data}

Data hasil analisis tanah di laboratorium (Tabel 4.) digunakan untuk penilaian kualitas tanah dan indikator yang berbeda atau berubah antara sawah intensif dan yang dikonversi menjadi kebun melalui beberapa tahapan. Pertama dilakukan pengkriteriaan faktor pembatasan dan pembobotan relative indikator kualitas tanah menurut kriteria Lal, 1994 (Tabel 3.2). Setelah ditentukan faktor pembatas dan bobot relatif dari masingmasing indikator kualitas tersebut,dilakukan penghitungan Indeks Kualitas Tanah (IKT) untuk mendapatkan nilai bobot komulatif. Selanjutnya ditentukan kriteria kualitas tanah berdasarkan Tabel 3.

Mengacu metode Lal (1994), sepuluh Minimum Data Set (MDS) yang menjadi penciri kunci dari kualitas tanah di wilayah tropis terdiri dari penciri sifat fisik tanah meliputi: tekstur, bobot isi, dan porositas; penciri kimia: KTK, KB, pH, N-total,P- tersedia; penciri biologi: C-Organik dan CBiomasaa.

Nilai indikator kualitas tanah berkisar dari angka 1 sampai 5. Batas bawah (bobot 1) untuk sifat tanah yang tidak memiliki faktor pembatas, sedangkan batas atas (bobot 5) memiliki banyak faktor pembatas. Berikut ini merupakan kriteria faktor pembatas dan pembobotan relatif indikator kualitas tanah menurut metode Lal,1994 yang dimodifikasi, disajikan pada Tabel 2. 
Tabel 2. Faktor Pembatas dan Pembobotan Relatif

\begin{tabular}{|c|c|c|c|c|c|c|}
\hline \multirow[b]{3}{*}{ No } & \multirow[b]{3}{*}{ Indikator } & \multicolumn{5}{|c|}{ Faktor pemb atas dan bobot relative } \\
\hline & & Tanpa & Ringan & Sedang & Berat & Ekstrim \\
\hline & & 1 & 2 & 3 & 4 & 5 \\
\hline 1 & Bobot isi $\left(\mathrm{gcm}^{-3}\right)$ & $<1,2$ & $1,2-1,3$ & $1,3-1,4$ & $1,4-1,5$ & $>1,5$ \\
\hline 2 & Tekstur tanah (\%) & $\mathrm{L}$ & SiL,Si,SiCL & $\mathrm{Cl}, \mathrm{SL}$ & $\mathrm{SiC}, \mathrm{LS}$ & $\mathrm{S}, \mathrm{C}$ \\
\hline 3 & $\begin{array}{l}\text { Porositas (\%) } \\
\text { pH }\end{array}$ & $>20$ & $18-20$ & $15-18$ & $10-15$ & $<10$ \\
\hline 4 & KTK (me 100g-1) & $6,0-7,0$ & $5,8-6,0$ & $5,4-5,8$ & $5,0-5,4$ & $<5,4$ \\
\hline 5 & $\begin{array}{l}\text { KB (\%) } \\
\text { P-tersedia (ppm) }\end{array}$ & $>40$ & $25-40$ & $17-24$ & $5-16$ & $<5$ \\
\hline 6 & $\begin{array}{l}\text { K-tersedia }(\%) \\
\text { N-total }(\%)\end{array}$ & $>70$ & $51-70$ & $36-50$ & $20-30$ & $<20$ \\
\hline 7 & C-organik (\%) & $>35$ & $26-35$ & $16-25$ & $10-15$ & $<10$ \\
\hline 8 & C-biomassa (mg CO2/kg) & $>1,0$ & $0,6-1,0$ & $0,3-0,5$ & $0,1-0,2$ & $<0,1$ \\
\hline 9 & & $>0,75$ & $0,51-0,75$ & $0,21-0,50$ & $0,10-0,20$ & $<0,10$ \\
\hline 10 & & $5-10$ & $3-5$ & $1-3$ & $0,5-1$ & $<0,5$ \\
\hline 11 & & $>25$ & $20-25$ & $10-20$ & $5-10$ & $<5$ \\
\hline
\end{tabular}

Sumber: modifikasi Lal (1994)

Keterangan: L=lempung; $\mathrm{Si}=\mathrm{Silt}$ (debu); $\mathrm{S}=$ sand (pasir); C=clay (liat)

Nilai IKT (Indeks Kualitas Tanah)

merupakan nilai komulatif yang dihitung berdasarkan penjumlahan masing-masing indikator fisik, kimia dan biologi tanah yang diamatai dengan persamaan:

\section{$\mathrm{IKT}=\mathrm{SF}+\mathrm{SK}+\mathrm{SB}$}

Keterangan:

IKT : Indeks Kualitas Tanah

SF : Faktor yang berhubungan dengan proses atau sifat fisik tanah

SK : Faktor yang berhubungan dengan proses atau sifat kimia tanah

SB : Faktor yang berhubungan dengan proses atau sifat biologi tanah 
I DEWA MADE ARTHAGAMADAN I MADE DANA. Evaluasi Kualitas Tanah Sawah Intensif dan...

Tabel 3. Kriteria Kualitas Tanah Berdasarkan Indeks Kualitas Tanah (IKT)

\begin{tabular}{|cc|}
\hline Kualitas Tanah & Indeks Kualitas Tanah (IKT) \\
Sangat Baik & $<20$ \\
Baik & $20 \times 25$ \\
Sedang & $25-30$ \\
Buruk & $30-40$ \\
Sangat Buruk & $>40$ \\
\hline
\end{tabular}

\section{HASIL DAN PEMBAHASAN}

Analisis sifat dasar tanah sebagai acuan untuk evaluasi kualitas tanah merupakan karakteristik atau proses fisika, kimia, dan biologi tanah yang dapat menggambarkan kondisi tanah. Hasil analisis indikator kualitas tanah yang diamati dari beberapa sifat fisisk, kimia, dan biologi tanah, minimal terdiri dari 10 parameter atau diistilahkan dengan Minimum Data Set (MDS) disajikan pada Tabel 4.
Indikator kualitas tanah yang dipilih dari sifat dasar tanah untuk memenuhi 10 MDS dari metode Lal, 1994 yang dimodifikasi menunjukkan kapasitas fungsi tanah atau faktor pembatas tanaman untuk berproduksi. Faktor pembatas tersebut berkisar dari ekstrim dengan nialai 5 hingga tanpa faktor pembatas nilai 1. Nilai faktor pembatas dan pembobotan relatif dari parameter sifat dasar tanah untuk penilaian Indeks Kualitas Tanah disajikan pada Tabel 5. 
AGROTROP, 10 (1): 1 - 10 (2020)

Tabel 4. Hasil Analisis Sifat Fisik, Kimia, dan Biologi Tanah

\begin{tabular}{|c|c|c|c|c|}
\hline \multirow[t]{2}{*}{ Parameter } & \multirow[t]{2}{*}{ Satuan } & \multirow[t]{2}{*}{ Metode } & \multicolumn{2}{|c|}{ Hasil } \\
\hline & & & SI & SK \\
\hline \multicolumn{5}{|l|}{ Sifat Fisik } \\
\hline 1. Tekstur tanah & $\%$ & Metode pipet & $\mathrm{Cl}$ & $\mathrm{CL}$ \\
\hline 2. Bobot isi & $\mathrm{gcm}^{-3}$ & Gravimetri & 0,910 & 0,963 \\
\hline 3. Porositas & $\%$ & Ring sampler & 50,60 & 54,40 \\
\hline \multicolumn{5}{|l|}{ Sifat Kimia tanah } \\
\hline 4. $\mathrm{pH}$ & & $\begin{array}{l}\text { Potensiometer (H2O 1:2,5) } \\
\text { Destilasi Kjeldahl }\end{array}$ & 6,1 & 6,0 \\
\hline 5. N-total & $\%$ & Bray-1 & 0,21 & 0,17 \\
\hline 6. P-tersedia & ppm & Ekstraksi NH4OAc $1 \mathrm{~N}$ pH7 & 209,80 & 9,60 \\
\hline 7. KTK & me $100 \mathrm{~g}^{-1}$ & Ekstraksi NH4OAc $1 \mathrm{~N} \mathrm{pH7}$ & 29,14 & 21,82 \\
\hline $\begin{array}{c}8 \mathrm{KR} \\
\text { Sifat Biologi tanah }\end{array}$ & & Walk lev\& Rlack & 0354 & 7936 \\
\hline 10. C-Biomassa mikroba & $\operatorname{mg~CO} 2 \mathrm{~kg}^{-1}$ & Simulasi Respirasi tanah & 10,35 & 9,15 \\
\hline
\end{tabular}

Keterangan CL : tekstur tanah Clay Loam (Lempung berliat) 
I DEWA MADE ARTHAGAMADAN I MADE DANA. Evaluasi Kualitas Tanah Sawah Intensif dan...

Tabel 5. Nilai Pembobotan Relatif Sifat Fisik, Kimia, dan Biologi TanahSerta Nilai IKT

\begin{tabular}{|c|c|c|c|}
\hline \multirow[t]{2}{*}{ Parameter } & \multirow[t]{2}{*}{ Satuan } & \multicolumn{2}{|c|}{$\begin{array}{l}\text { Hasil dan pembobotan relative parameter } \\
\qquad \operatorname{tanah}\end{array}$} \\
\hline & & SI & SK \\
\hline \multicolumn{4}{|l|}{ Sifat Fisik } \\
\hline 1. Tekstur tanah & $\%$ & $\mathrm{Cl}(3)$ & CL (3) \\
\hline 2. Bobot isi & $\mathrm{gcm}^{-3}$ & $0,910(1)$ & $0,963(1)$ \\
\hline 3. Porositas & $\%$ & $50,60(1)$ & $54,40(1)$ \\
\hline \multicolumn{4}{|l|}{ Sifat Kimia tanah } \\
\hline 4. $\mathrm{pH}$ & & $6,1(1)$ & $6,0(1)$ \\
\hline 5. N-total & $\%$ & $0,21(2)$ & $0,17(3)$ \\
\hline 6. P-tersedia & ppm & $209,80(1)$ & $9,60(5)$ \\
\hline 7. KTK & me $100 \mathrm{~g}^{-1}$ & $29,14(2)$ & $21,82(3)$ \\
\hline 8. $\mathrm{KB}$ & $\%$ & $93,54(1)$ & $79,36(1)$ \\
\hline 9. C-organik & $\%$ & 4,97 (2) & $3,06(2)$ \\
\hline \multicolumn{4}{|l|}{ Sifat Biologi tanah } \\
\hline 10. C-Biomassa mikroba & $\mathrm{mg} \mathrm{CO}^{2} \mathrm{~kg}^{-1}$ & & \\
\hline IKT & - & 18 & 25 \\
\hline
\end{tabular}

Keterangan: angka dalam kurung adalah nilai pembobotan parameter tanah

\section{Hasil Analisis}

\section{Indikator Sifat Fisik Tanah}

Pewakil indikator kualitas tanah dari parameter sifat fisik tanah adalah, tekstur tanah, bobot isi, dan porositas untuk memenuhi 10 MDS. Tabel 5. menunjukkan bahwa semua parameter sifat fisik tanah tidak berbeda jauh antara sawah intensif dan sawah yang dikonversikan kekebun, tekstur tanah tergolong sama yaitu lempung berliat dengan nilai pembobotan relatif tiga, demikian pula bobot isi dan porositas tanah bobot relatifnya sama satu, namun secara kuantitatif bobot isi sawah intensif (SI) lebih kecil, dan porositasnya lebih tinggi dari konversi sawah menjadi kebun ini berarti tanah sawah lebih mudah diolah, memiliki sistem drainase seta aerasi lebih baik (Utomo, 2015).

\section{Indikator Sifat Kimia Tanah}

Sifat kimia tanah sebagai parameter pewakil penentu kualitas tanah adalah: $\mathrm{pH}$, KTK, KB, N-total, P-tersedia dan C-organik tanah. C-organik, KB, dan $\mathrm{pH}$ tanah sawah intensif memiliki bobot nilai sama dengan sawah yang dikonversi kekebun yaitu masing- 
masing 2,1 dan 1, tetapi secara kwantitatif angkanya lebih besar (Tabel 5.2). Sifat kimia tanah sebagai penentu dan pembeda kualitas tanah adalah KTK, N-total, P-tersedia. Pada sawah intensif KTK tergolong tinggi dengan bobot nilai relatif dua, sedangkan konversi sawah menjadi kebun tergolong sedang dengan bobot nilai relatif tiga; pada parameter

N-total sawah intensif tergolong sedang dengan bobot nilai tiga namun konversi sawah kekebun tergolong rendah dengan bobot nilai empat; P-tersedia untuk tanah sawah intensif tergolong sangat tinggi dengan bobot nilai satu sedangkan pada sawah yang dikonversi kekebun tergolong sedang dengan bobot nilai lima. Perbedaan nilai bobot ketiga parameter kimia tersebut akan sangat menentukan kualitas tanah yang sedang dievaluasi. Nilai IKT sifat kimia tanah sawah intensif adalah 10 lebih kecil dari IKT tanah sawah yang dikonversi kekebun yaitu 16 .

\section{Indikator Sifat Biologi Tanah.}

Nilai bobot indikator sifat biologi tanah yang diukur berdasarkan C-biomassa tanah sawah intensif lebih kecil daripada konversi sawah kekebun. Bisa diartikan jumlah mikroba dalam tanah sawah intensif lebih banyak daripada konversi sawah kekebun, hal ini didukung oleh $\mathrm{N}$-total dan P-tersedia tanah sawah intensif lebih tingggi sehingga jaminan kebutuhan unsur bagi mikroba tanah lebih banyak,disamping itu sifat fisik tanah dari segi aerasi tanah sawah intensif lebih bagus.

\section{Hasil Evaluasi Kualitas Tanah}

Berdasarkan hasil evaluasi kualitas tanah sawah intensif dan sawah yang dikonversikan menjadi kebun di Subak Kesiut, Desa Kesiut Kecamatan Kerambitan Kabupaten Tabanan dihitung nilai IKT dengan penjumlahan indikator sifat fisik, kimia, dan biologi tanah maka sawag intensif (SI).nilai IKT $=5+3+10=18$, konversi sawah menjadi kebun (SK) nilai IKTnya $=5+16+4=25$. Secara komulatif nilai IKT sawah intensif 18 jauh lebih kecil dari pada nilai IKT konversi sawah dijadikan kebun yaitu 25, berarti kualitas tanah sawah intensif masih lebih bagus dibandingkan yang dikonversikan menjadi kebun faktor pembatasnya lebih sedikit, hal ini didukung sistem managemen tanah sawah intensif lebih bagus karena setiap musim tanam tanah sawah rutin dilakukan pemupukan dan pengembalian hasil sisa-sisa panen sehingga kadar $\mathrm{P}$ tersedia tanah lebih tinggi. 
I DEWA MADE ARTHAGAMADAN I MADE DANA. Evaluasi Kualitas Tanah Sawah Intensif dan...

\section{SIMPULAN}

Berdasarkan hasil penelitian ini maka dapat disimpulkan sebagai berikut: Kualitas tanah sawah intensif lebih bagus dari pada yang dikonversikan menjadi kebun ditunjukkan dengan angka IKT sawah intensif 18 lebih rendah dari IKT sawah yang dikonversikan menjadi kebun yaitu 25, kadar $\mathrm{P}$ tersedia tanah sawah lebih tinggi dari pada yang dijadikan kebun, sehingga sistem sawah yang ada di Subak Kesiut perlu dijaga dan dilestarikan.

\section{DAFTAR PUSTAKA.}

Lal,R. 1994. Methods And Guidelines for Assessing Sustainable Use of Soil and Water Resource in Tropics. Washingyon: Soil Managemen Suport USDA Soil Conservation Service.

Prasetyo,B.H, Ningsih.J.S.,Subagyono,K., dan Simangnukalit,R.D.M.,2004. Mineralogi, Kimia dan Biologi Tanah.

Reintjes,C.B. Haverkot, dan A.W. Bayer. 1999. Pertanian masa depanILEIA. Kanisius, Jogjakarta.

Sandi Adnyana, I Wayan; I Wayan Arthana; Abd. Rahman As-Syakur, 2011. Perubahan Penggunaan Lahan dan Daya Dukung ingkungan. PPLH Universitas Udayana. Udayna University Press. 2011.

Sofyan,A.,Nurjaya dan A.Kusno. 2007. Status Hara Tanah Sawah untuk rekomendasi pemupukan dan teknologi pengelolaannya. Pusat Penelitian dan Pengembangan Tanah Agroklimat. Bogor.
Suparta,2017. Alih Fungsi Lahan Sawah di Bali. Jumat,17 Maret 2017 18.52 WIB m.kbr.id/nusantara/03-2017. Diunduh 08Pebruari 2018.

Utomo,M. 2002. "Pengelolaan lahan kering untuk pertanian berkelanjutan" Makalah dalam lokakarya kurikulum inti Fakultas Pertanian se-Indonesia. Mataram-NTB, 26-28 Mei 2002.

Utomo,M ,dkk. 2015. Ilmu Tanah Dasardasar Pengelolaannya. Prenadamedia Group Jakarta. 